\title{
Mediobasal Hypothalamic Leucine Sensing Regulates Food Intake through Activation of a Hypothalamus-Brainstem Circuit
}

\author{
Clémence Blouet, ${ }^{1}$ Young-Hwan Jo, ${ }^{1,2}$ Xiaosong Li, ${ }^{1}$ and Gary J. Schwartz ${ }^{1,2}$ \\ Departments of ${ }^{1}$ Medicine and ${ }^{2}$ Neuroscience, Albert Einstein College of Medicine of Yeshiva University, Bronx, New York 10461
}

\begin{abstract}
In response to nutrient stimuli, the mediobasal hypothalamus (MBH) drives multiple neuroendocrine and behavioral mechanisms to regulate energy balance. While central leucine reduces food intake and body weight, the specific neuroanatomical sites of leucine sensing, downstream neural substrates, and neurochemical effectors involved in this regulation remain largely unknown. Here we demonstrate that MBH leucine engages a neural energy regulatory circuit by stimulating POMC (proopiomelanocortin) neurons of the MBH, oxytocin neurons of the paraventricular hypothalamus, and neurons within the brainstem nucleus of the solitary tract to acutely suppress food intake by reducing meal size. We identify central p70 S6 kinase and Erk1/2 pathways as intracellular effectors required for this response. Activation of endogenous leucine intracellular metabolism produced longer-term reductions in meal number. Our data identify a novel, specific hypothalamus- brainstem circuit that links amino acid availability and nutrient sensing to the control of food intake.
\end{abstract}

\section{Introduction}

The hypothalamus has emerged as a major center of convergence and integration of nutrient-related signals, critical in determining whole-body energy homeostasis (Morton et al., 2006). Subpopulations of hypothalamic neurons not only are sensitive to adiposity hormones, such as insulin and leptin, but are also responsive to glucose and fatty acids, and these nutrients act as signaling molecules to determine membrane potential and firing rate, thereby driving downstream behavioral and metabolic effectors of energy balance (Obici et al., 2002; Ibrahim et al., 2003; Wang et al., 2004; Jo et al., 2009). Hypothalamic nutrient sensing is impaired in animal models of obesity, and disruption of hypothalamic nutrient sensing induces obesity and dysregulation of glucose homeostasis (He et al., 2006; Parton et al., 2007). Conversely, restoration of hypothalamic nutrient sensing normalizes food intake, energy balance, and glucose homeostasis in overfed rats (Pocai et al., 2006). Together, these findings underscore the relevance of hypothalamic nutrient sensing in the regulation of energy balance and the pathophysiology of obesity and metabolic diseases, and emphasize the need to identify and characterize how these sensors are linked to intercellular and intracellular neural circuits that affect behavioral and physiological determinants of energy balance.

Recent data indicate that brain amino acid sensing also con-

Received April 6, 2009; revised May 5, 2009; accepted May 24, 2009.

This work was supported by National Institutes of Health (NIH) Grant DK 047208, the New York Obesity Research Center (NIH Grant DK026687), the Albert Einstein College of Medicine Diabetes Research and Training Center (NIH Grant DK 020541), and the Skirball Institute for Nutrient Sensing. We thank Profs. Daniel Tomé and Susan M. Hutson for providing us with reagents.

This article is freely available online through the J Neurosci Open Choice option.

Correspondence should be addressed to Dr. Gary J. Schwartz, Department of Medicine, Albert Einstein College of Medicine of Yeshiva University, 1300 Morris Park Avenue, Golding 501, Bronx, NY 10461. E-mail: gjschwar@aecom.yu.edu.

D0I:10.1523/JNEUROSCI.1668-09.2009

Copyright $\odot 2009$ Society for Neuroscience $\quad$ 0270-6474/09/298302-10\$15.00/0 tributes to the homeostatic regulation of food intake and body weight, and suggest that amino acid-induced activation of the hypothalamic mammalian target of rapamycin complex 1 (mTORC1) pathway mediates these effects (Cota et al., 2006). However, the role of hypothalamic neurons in brain amino acid sensing remains unclear, and the neurobiological substrates and physiological effectors mediating metabolic and behavioral consequences of neuronal amino acid sensing are unknown.

Leucine, one of the three branched-chain amino acids, is likely to represent a physiological signal of hypothalamic amino acid availability. Dietary leucine largely escapes first-pass metabolism, plasma leucine levels are rapidly and markedly increased in the postprandial state (Brosnan and Brosnan, 2006), and leucine enters the brain more quickly than other amino acids (Kanamori et al., 1998). Among amino acids, leucine is the most potent activator of the amino-acid-sensitive mTORC1 pathway (Proud, 2004) and represents a signal of amino acid abundance for various anabolic pathways, including protein synthesis (Nair et al., 1992), gene transcription and translation (Kimball and Jefferson, 2006), and insulin secretion (Henquin et al., 2006).

In the current work, we determined for the first time the effects of endogenous mediobasal hypothalamic $(\mathrm{MBH})$ leucine sensing on food intake and energy expenditure in rodents, identified a forebrain/hindbrain neurocircuit engaged by $\mathrm{MBH}$ leucine to contribute to the homeostatic feedback control of energy balance, and characterized intracellular and interneuronal mechanisms that mediate the ability of $\mathrm{MBH}$ leucine sensing to affect food intake and body weight. These data link for the first time hypothalamic nutrient sensors to brainstem effectors of food intake, and provide a more general experimental framework for identifying critical signaling pathways linking hypothalamic nutrient sensing to behavioral determinants of energy balance. 


\begin{abstract}
Materials and Methods
Animals and reagents

Male C57BL/6 mice and Sprague Dawley rats were obtained at 10 weeks of age respectively from The Jackson Laboratory and Charles River Laboratories. POMC-CRE Z/eGFP mice, wherein the POMC-CRE transgene causes cell-specific recombination to induce expression of eGFP from the $\beta$-actin promoter, were obtained as previously described (Jo et al., 2009). All animals were housed in individual cages and maintained in a temperature-controlled room under a standard $12 \mathrm{~h} / 12 \mathrm{~h}$ light/dark cycle with ad libitum access to water and standard chow unless specifically indicated. Animals dedicated to signaling studies were trained daily to be hooked up to the brain injection system for at least the 4 consecutive days preceding the injection to avoid a stress-related increase in the signal-tonoise ratio. All experimental protocols were approved by the Institute for Animal Studies of the Albert Einstein College of Medicine. All chemicals were obtained from Sigma, and all antibodies were purchased from Cell Signaling Technology, unless otherwise specified.
\end{abstract}

\section{Postprandial plasma and CSF amino acid determination}

Rats were trained to eat within $1 \mathrm{~h}$ a $10 \mathrm{~g}$ calibrated meal of a standard normal-protein diet (NP) supplemented with $4 \%$ leucine or a highprotein diet (HP) containing $530 \mathrm{~g}$ of protein $/ \mathrm{kg}$ of food (gift from Prof. Daniel Tomé, AgroParisTech, Paris, France) after a 24 h fast. The NP leucine-supplemented meal and the HP meal provided 508 and $420 \mathrm{mg}$ of leucine, respectively. On the day of the experiment, rats fasted for 24 or $1 \mathrm{~h}$ refed with the meal of the training period were anesthetized with ketamine/xylazine. CSF was collected as previously described (Lugarini et al., 2002) and blood sampled by cardiac puncture. Amino acid concentrations were determined by Scientific Research Consortium.

\section{CNS surgery}

Surgical procedures were performed under ketamine/xylazine anesthesia. Animals were stereotaxically implanted with a steel guide cannula (Plastics One) into the third ventricle (rat coordinates from bregma: A/P $-2.5 \mathrm{~mm}, \mathrm{D} / \mathrm{V}-8.5 \mathrm{~mm}$ ), the fourth ventricle (mouse coordinates from bregma: A/P $-6 \mathrm{~mm}, \mathrm{D} / \mathrm{V}-4 \mathrm{~mm}$ ), or a bilateral cannula targeting the $\mathrm{MBH}$ (mouse coordinates from bregma: $\mathrm{A} / \mathrm{P}-1.1 \mathrm{~mm}, \mathrm{D} / \mathrm{V}-5.9 \mathrm{~mm}$; rat coordinates from bregma: A/P $-3.0 \mathrm{~mm}, \mathrm{D} / \mathrm{V}-10.4 \mathrm{~mm}$ ). For chronic drug administration, the guide cannula was connected to an osmotic pump (model 1002, Alzet) via a cannula bifurcation connector (Plastics One). Animals were allowed a 1 week recovery. Accurate rat third ventricle cannula placement was confirmed by consumption of $>5$ $\mathrm{ml}$ of water within $60 \mathrm{~min}$ following an intracerebroventricular administration of $10 \mathrm{ng}$ of angiotensin in $2 \mu \mathrm{l}$ of artificial CSF (aCSF, Harvard Apparatus). Correct bilateral $\mathrm{MBH}$ and individual fourth intracerebroventricular cannula placement was confirmed histologically postmortem by India ink injections of $200 \mathrm{nl}$ (rat) or $100 \mathrm{nl}$ (mouse).

\section{Feeding behavior studies and injection designs}

Before all experiments, animals were adapted for 1 week to individual feeding chambers (Med Associates) with ad libitum access to a standard chow diet (Bioserv 20 and $45 \mathrm{mg}$ precision pellets, F05524 and F0165). Meal patterns were determined as previously described (Azzara et al., 2002). Seven distinct brain injection designs were used, as outlined below. In acute injection experiments, all animals received all drugs in a crossover manner, and at least $4 \mathrm{~d}$ elapsed between each injection.

Injection design 1 . Mice fasted for $6 \mathrm{~h}$ and rats fasted overnight received a 5 min $\mathrm{MBH}$ injection (100 $\mathrm{nl}$ in mice and $200 \mathrm{nl}$ in rats, per side) of aCSF alone or together with $2.1 \mathrm{~mm}$ L-leucine (i.e., $28 \mathrm{ng}$ of leucine $=210$ pmol per side in mice), L-valine, $\alpha$-ketoisocaproic acid (KIC), or $\alpha$-ketoisovaleric acid (KIV) $1 \mathrm{~h}$ before the onset of the dark. Injections were site specific to the $\mathrm{MBH}$ and did not reach the paraventricular nucleus of the hypothalamus (PVN), lateral hypothalamus (LH), or dorsomedial hypothalamus (DMH) (supplemental Fig. 1, available at www. jneurosci.org as supplemental material). Access to food was restored immediately after the injection, food intake was continuously recorded for the following $24 \mathrm{~h}$, and body weight was measured before and $24 \mathrm{~h}$ after the MBH injection.

Injection design 2. Mice were implanted with an osmotic minipump delivering into the MBH $0.25 \mu \mathrm{l} / \mathrm{h}$ aCSF alone or together with $5.2 \mathrm{~mm}$ $\alpha$-chloroisocaproic acid for 2 weeks (CIC, gift from Prof. Susan Hutson, Wake Forest University, Winston-Salem, NC).

Injection design 3. SHU9119 (Bachem) or aCSF was injected into the MBH $3 \mathrm{~h}$ before dark onset ( $0.3 \mathrm{nmol}$ in $100 \mathrm{nl}$ of aCSF, per side), and leucine injection followed $2 \mathrm{~h}$ later as described above.

Injection design 4. Mice fasted for $6 \mathrm{~h}$ received $\left[\mathrm{D}-\left(\mathrm{CH}_{2}\right)_{5}, \mathrm{Tyr}(\mathrm{Me})^{2}, \mathrm{Orn}^{8}\right]-$ vasotocin (OVT, Bachem; 100, 500, or $1000 \mathrm{ng}$ ) or aCSF into the fourth ventricle just before dark onset, and access to food was restored immediately after the injection.

Injection design 5. OVT or aCSF was injected into the fourth ventricle $90 \mathrm{~min}$ before dark onset (1000 ng in $100 \mathrm{nl}$ of aCSF), and leucine injection followed $30 \mathrm{~min}$ later as described in injection design 1.

Injection design 6. Mice fasted for $6 \mathrm{~h}$ received U0126 (Promega) or its vehicle into the MBH 90 min before dark onset ( 25 or $250 \mathrm{ng}$ in $150 \mathrm{nl}$ of DMSO:saline, 1:1, per side), and access to food was restored $30 \mathrm{~min}$ after the injection.

Injection design 7. U0126 or its vehicle was injected into the MBH 90 min before dark onset ( $25 \mathrm{ng}$ in $150 \mathrm{nl}$ of DMSO:saline, 1:1, per side), and leucine injection followed $30 \mathrm{~min}$ later as described in injection design 1.

\section{Conditioned taste aversion test}

On 2 different experimental days separated by 1 week, 24 h waterdeprived rats received a $2 \mu \mathrm{l}$ intracerebroventricular injection of aCSF or $4.12 \mathrm{~mm}$ KIC and were then presented with $1 \%$ almond- or vanillaflavored water in a Latin square design, almond and vanilla (McCormick) being equally palatable to naive rats (Bensaïd et al., 2003). Fluid intake was measured at $15,30,45$, and 60 min following the intracerebroventricular injection, and the placement of the two water bottles was changed at every reading time point to avoid any side preference. The preference ratio was calculated as the intake of KIC-paired flavored water over the total fluid intake. We controlled for our ability to induce a taste aversion using a similar design in a separate group of rats that received an intraperitoneal injection of saline or $0.15 \mathrm{M} \mathrm{LiCl}$ in a volume equivalent to $2 \%$ of the rat's body weight.

\section{Indirect calorimetry}

Under isoflurane anesthesia, mice were implanted with an intraperitoneal radio-frequency impedance temperature probes (Minimitter) and then adapted to individual metabolic chambers. Metabolic measurements (oxygen consumption, carbon dioxide production, food intake, core temperature, and locomotor activity) were obtained continuously using a CLAMS (Columbus Instruments) open-circuit indirect calorimetry system for $7 \mathrm{~d}$ before the first brain injection. The effects of $\mathrm{MBH}$ aCSF, leucine, and KIC injection on metabolism were assessed using Injection design 1.

\section{Slice preparation}

Slices were prepared for in vitro recordings as previously described (Jo et al., 2009). Transverse brain slices were prepared from POMC-CRE Z/eGFP mice at postnatal age $21-28 \mathrm{~d}$. Animals were anesthetized with a mixture of ketamine and xylazine. After decapitation, the brain was transferred into a sucrose-based solution bubbled with $95 \% \mathrm{O}_{2}-5 \% \mathrm{CO}_{2}$ and maintained at $\sim 3^{\circ} \mathrm{C}$. This solution contained the following (in $\mathrm{mm}$ ): 248 sucrose, $2 \mathrm{KCl}, 1 \mathrm{MgCl}_{2}, 1.25 \mathrm{KH}_{2} \mathrm{PO}_{4}, 26 \mathrm{NaHCO}_{3}, 1$ sodium pyruvate, and 10 glucose. Transverse coronal brain slices $(200 \mu \mathrm{M})$ were prepared using a vibratome. Slices were equilibrated with an oxygenated aCSF for $>1 \mathrm{~h}$ at $32^{\circ} \mathrm{C}$ before transfer to the recording chamber. The slices were continuously superfused with aCSF at a rate of $1.5 \mathrm{ml} / \mathrm{min}$ containing the following (in mM): $113 \mathrm{NaCl}, 3 \mathrm{KCl}, 1 \mathrm{NaH}_{2} \mathrm{PO}_{4}, 26$ $\mathrm{NaHCO}_{3}, 2.5 \mathrm{CaCl}_{2}, 1 \mathrm{MgCl}_{2}$, and 5 glucose in $95 \% \mathrm{O}_{2} / 5 \% \mathrm{CO}_{2}$ at room temperature.

\section{Electrophysiological recordings}

Brain slices were placed on the stage of an upright, infrared-differential interference contrast microscope (Olympus BX50WI) mounted on a Gibraltar $X-Y$ table (Burleigh) and visualized with a $40 \times$ waterimmersion objective by infrared microscopy (DAGE MTI camera). Membrane potentials were recorded at room temperature $\left(25-26^{\circ} \mathrm{C}\right)$ with an Axopatch 200B Patch-Clamp amplifier. The internal solution 
contained the following (in $\mathrm{mm}$ ): $115 \mathrm{~K}$-acetate, $10 \mathrm{KCl}, 2 \mathrm{MgCl}_{2}, 0.2$ EGTA, 10 HEPES, $1 \mathrm{Na}_{2}$ ATP, $0.5 \mathrm{Na}_{2} \mathrm{GTP}$, and 5 phosphocreatine. Pipette resistance ranged from 2.5 to $4 \mathrm{M} \Omega$. L-Leucine was purchased from Fluka and dissolved in water at $1000 \times$ the final concentration.

Tissue collection for immunostaining

POMC-CRE Z/eGFP and C57BL/6 mice fasted for $6 \mathrm{~h}$ received a $100 \mathrm{nl}$ $\mathrm{MBH}$ injection of aCSF alone or together with $2.06 \mathrm{~mm}$ leucine and were killed 30-70 min later with pentobarbital. Brains were perfused transcardially via a 23 gauge needle placed in the left ventricle with $200 \mathrm{ml}$ of 0.1 м PBS, pH 7.4, followed by $200 \mathrm{ml}$ of $4 \%$ paraformaldehyde in PBS, and the fixed brains were cryoprotected in $30 \%$ sucrose. Coronal hypothalamic sections of $35 \mu \mathrm{m}$ thickness were prepared on a freezing microtome.

\section{c-Fos immunocytochemical staining}

Free floating sections were incubated in $0.3 \%$ hydrogen peroxide for 15 min, blocked with $10 \%$ normal goat antiserum (NGS), and then incubated in c-Fos antiserum (1:10,000 dilution, AB-5, Oncogene) with $0.3 \%$ Triton X-100 and $10 \%$ NGS in PBS for $48 \mathrm{~h}$ at $4^{\circ} \mathrm{C}$ with gentle agitation. For light microscopy, sections were then incubated using standard biotinylated goat anti-rabbit IgG and avidin-biotin-peroxidase complex (Elite Vectastain kit, Vector Laboratories). Reaction product was visualized using nickel sulfate-enhanced diaminobenzidine as the chromogen (Emond et al., 2001). For immunofluorescence, after primary c-Fos antibody incubation, sections were exposed for $2 \mathrm{~h}$ to $\mathrm{Cy} 3$-conjugated goat anti-rabbit IgG (1:200; Jackson ImmunoResearch), washed in PBS, floated onto gelatinized slides, and coverslipped with Vectashield (Vector Laboratories). Native GFP and Cy3 fluorescence were visualized with the appropriate lasers and emission filters on a LSM 510 NLO multiphoton confocal microscope (Zeiss).

\section{Oxytocin and phospho-Erk1/2 double labeling}

Free floating sections were incubated for $15 \mathrm{~min}$ in $0.3 \%$ hydrogen peroxide before being incubated overnight at room temperature in rabbit anti-phospho-Erk1/2 IgG (1:500, Cell Signaling technology) and guineapig anti-oxytocin IgG (1:2500, Bachem) in $0.3 \%$ Triton X-100 and $3 \%$ NGS. Sections were then incubated for $2 \mathrm{~h}$ with Cy2-conjugated goat anti-guinea pig IgG (1:200, Jackson ImmunoResearch) and Cy3conjugated goat anti-rabbit IgG (1:200), floated onto gelatinized slides, and coverslipped with Vectashield.

\section{Image analysis}

Images of tissue sections were digitized, and areas of interest were outlined based on cellular morphology. c-Fos-positive nuclei within the regions of interest were quantified with automated image analysis software (NIH Image and Zeiss Axiovision 4.6 software), and c-Fos-positive cells were automatically counted by the imaging programs by setting minimum and maximum optical density levels. Brain regions evaluated were $\mathrm{LH}(0.7-0.8 \mathrm{~mm}$ caudal to bregma), PVN (0.7-0.8 mm caudal to bregma), supraoptic nucleus ( $\mathrm{SON}, 0.6-0.7 \mathrm{~mm}$ caudal to bregma), arcuate nucleus (1.8-1.9 mm caudal to bregma), DMH (1.7-1.8 $\mathrm{mm}$ caudal to bregma), and the nucleus of the solitary tract (NTS) at the midlevel of the area postrema (7.3-7.4 mm caudal to bregma), corresponding to the coordinates in the brain atlas of Paxinos and Franklin (2001), and were based on six animals/group.

\section{Micropunch dissection}

Using a McIlwain tissue chopper, $800-\mu \mathrm{m}$-thick hypothalamic and brainstem sections were prepared from freshly extracted mouse brain. Sections were placed on a stainless steel plate cooled by liquid nitrogen and immersed in liquid nitrogen for $2 \mathrm{~s}$, and the micropunches were dissected out. The hypothalamic section containing the MBH spanned from approximately -1.25 to $-2.05 \mathrm{~mm}$ posterior to bregma (Paxinos and Franklin, 2001), and we collected an equilateral triangle with the altitude defined as one-third of the ventral side of the third ventricle, including the median eminence. The hypothalamic section containing the PVN spanned from approximately -0.45 to $-1.25 \mathrm{~mm}$ posterior to bregma (Paxinos and Franklin, 2001), and we collected an equilateral triangle with the altitude defined as one-third of the dorsal side of the third ventricle. The brainstem section spanned the rostrocaudal extent of the area postrema, from approximately -7.2 to $-8.0 \mathrm{~mm}$ posterior to bregma (Paxinos and Franklin, 2001). The cerebellum was quickly removed with fine forceps. The spinal trigeminal nuclei forming the lateral borders of the section were excised and discarded. The remaining brainstem slice was then excised horizontally at the ventral aspect of the central canal, dissecting the dorsal vagal complex (DVC) from the more ventral hypoglossal nucleus and basal brainstem. The remaining DVC, including the area postrema, the NTS, and the dorsal motor vagal nucleus, was collected. All micropunches were snap frozen in liquid nitrogen.

\section{Western blot analysis}

Western blot analyses were performed as previously described (Blouet et al., 2008). Briefly brain micropunches were homogenized in $50 \mathrm{~mm}$ Tris, $1 \mathrm{~mm}$ EGTA, $1 \mathrm{~mm}$ EDTA, $50 \mathrm{~mm}$ sodium fluoride, $10 \mathrm{~mm}$ $\beta$-glycerophosphate, $20 \mathrm{~mm}$ sodium pyrophosphate, $2 \mathrm{~mm}$ orthovanadate, 2 mm PMSF, $1 \%$ Triton, and Complete phosphatase inhibitor cocktail (Roche). Protein extracts $(10-20 \mu \mathrm{g})$ were run on Criterion gels (Bio-Rad) and blotted onto nitrocellulose membranes. Immunoblots were incubated in primary antibodies against phospho-p70 S6 kinase (Thr389), phospho-S6 ribosomal protein (Ser235/236), phospho-Erk1/2 (Thr202/Tyr204), Erk1/2, phospho-CREB (Ser133), CREB, p70 S6 kinase (Millipore), or $\beta$-actin (Santa Cruz Biotechnology) IgG, followed by an incubation in fluorescent (Rockland Immunochemicals) or HRPlinked secondary antibodies. Proteins were detected using either the fluorescence-based Odyssey Infrared Imaging System (LI-COR Biosciences) or enhanced chemiluminescence (ECL Plus, GE Healthcare).

\section{Statistical analysis}

All data, presented as means \pm SEM, were analyzed using GraphPad Prism 5. For all statistical tests, an $\alpha$ risk of 5\% was used. All kinetics were analyzed using a mixed model for repeated measurements. Multiple comparisons were tested with an ANOVA and adjusted with Tukey posttest. Single comparisons were made using one-tail Student $t$ tests.

\section{Results}

\section{Dietary leucine increases CSF leucine concentration}

To begin to assess the physiological role of central leucine in the negative feedback control of food intake within the time frame of an individual meal, we measured meal-related changes in CSF leucine availability in rat. In the fasted state, CSF leucine concentration was 26 times lower than plasma leucine (supplemental Fig. 2, available at www.jneurosci.org as supplemental material). The ingestion of a HP meal rapidly induced a twofold increase in plasma leucine concentration and a $24 \%$ increase in CSF leucine level. Following the ingestion of a standard chow $4 \%$ leucineenriched meal, plasma leucine concentration was further increased (3-fold increase compared with fasted level), and this induced a $44 \%$ increase in CSF leucine concentration. Thus, during a meal, dietary leucine rapidly increases CSF leucine levels in parallel with increases in plasma leucine.

\section{$\mathrm{MBH}$ leucine administration reduces food intake and body weight}

We next determined the consequences of increased $\mathrm{MBH}$ leucine availability on several behavioral and metabolic effectors of energy balance. In both rat and mouse, $\mathrm{MBH}$ leucine administration induced a significant reduction in $24 \mathrm{~h}$ food intake (Fig. $1 a, e$ ), and decreased $24 \mathrm{~h}$ body weight change (Fig. $1 b, f$ ) compared with aCSF vehicle injections. The decrease in food intake was due to both a reduction in meal size (Fig. $1 c, g$ ) - including a dramatic 50\% reduction in the first meal size, occurring during the first 20 min following the injection in both rats and miceand a sustained decrease in meal number beginning $8 \mathrm{~h}$ after the injection that persisted for $24 \mathrm{~h}$ after injection (Fig. $1 d, h$ ).

$\mathrm{MBH}$ injection of an equimolar dose of KIC, the product of 

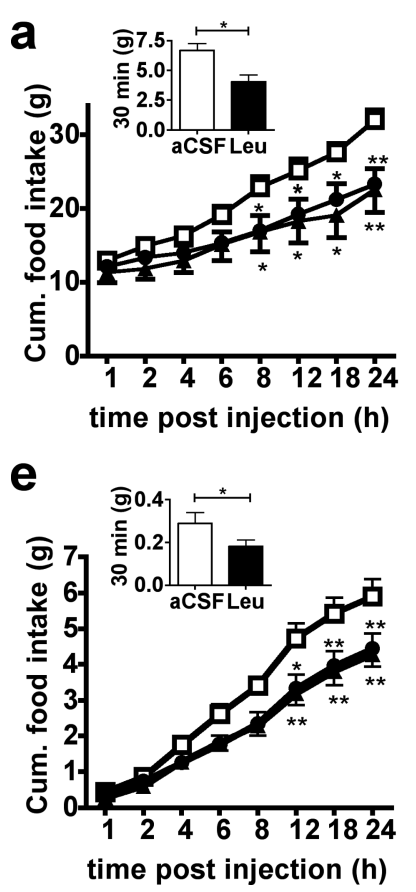

b

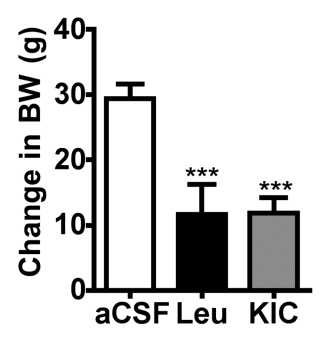

$f$

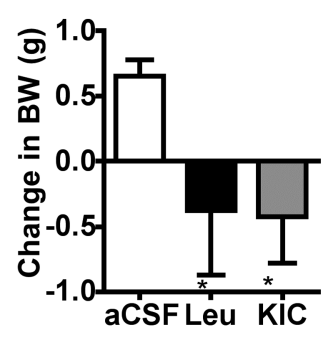

C

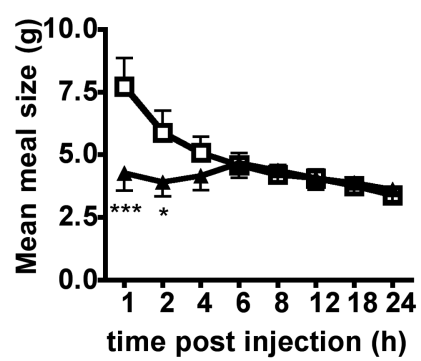

g

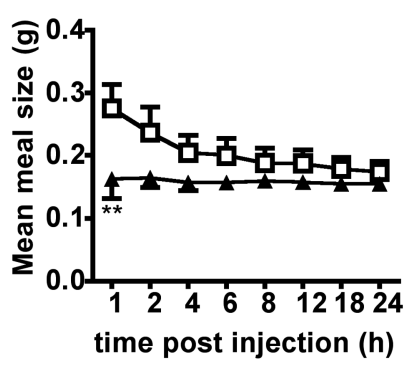

d
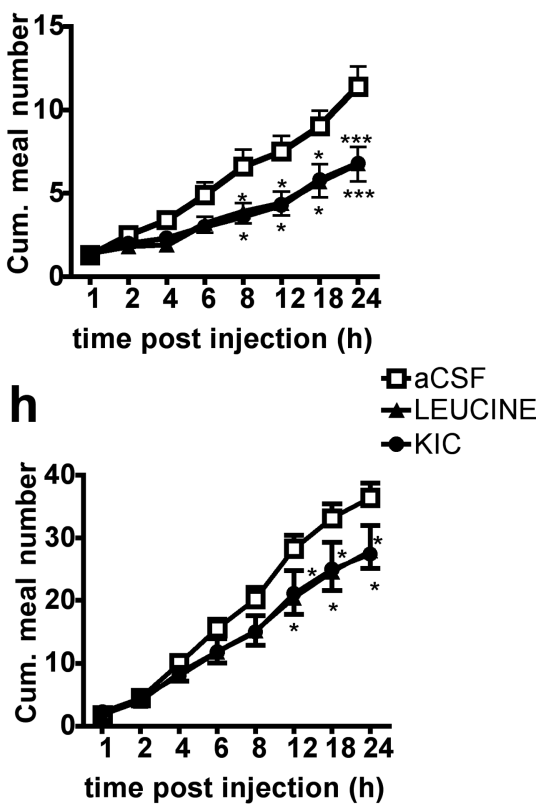

Figure 1. MBH leucine and KIC injections reduce food intake and body weight in rat and mouse. $\boldsymbol{a}-\boldsymbol{h}$, Cumulative (Cum.) food intake ( $\boldsymbol{a}, \boldsymbol{e}), 24 \mathrm{~h}$ change in body weight (BW) $(\boldsymbol{b}, \boldsymbol{f})$, mean meal size $(\boldsymbol{c}, \boldsymbol{g})$, and cumulative meal number $(\boldsymbol{d}, \boldsymbol{h})$ in rat $(\boldsymbol{a}-\boldsymbol{d}, n=10-12)$ and mouse $(\boldsymbol{e}-\boldsymbol{h}, n=8)$ following an MBH injection of aCSF, leucine, or KIC (injection design 1$)$. Data are means \pm SEM. ${ }^{*} p<0.05$ versus aCSF; ${ }^{* *} p<0.01$ versus aCSF; ${ }^{* * *} p<0.001$ versus aCSF.

leucine reversible transamination by branched-chain amino-acid transferase (BCAT), recapitulated the effects of $\mathrm{MBH}$ leucine injection on $24 \mathrm{~h}$ food intake (Fig. 1a,e), 24 h body weight change (Fig. $1 b, f$ ), and meal number (Fig. $1 d, h$ ) but did not affect meal size (data not shown); these results support the interpretation that endogenous $\mathrm{MBH}$ leucine metabolism reduces food intake and body weight. Previous data reported that intracerebroventricular leucine-induced anorexia is not accompanied by visceral illness (Cota et al., 2006); likewise, intracerebroventricular KICinduced anorexia was not due to the development of conditioned taste aversion (supplemental Fig. 3, available at www.jneurosci. org as supplemental material).

To assess the specificity of the MBH leucine response with respect to other branched-chain amino acids, we examined the feeding inhibitory effects of the nonketogenic branched-chain amino acid valine, and its ketoacid, KIV. Both valine and KIV failed to alter food intake and body weight change compared with aCSF control injections (supplemental Fig. $4 a, b$, available at www.jneurosci.org as supplemental material).

The decreases in $24 \mathrm{~h}$ food intake following $\mathrm{MBH}$ leucine and KIC administrations were not accompanied by significant changes in respiratory quotient, oxygen consumption, core temperature, or locomotor activity compared with aCSF control injection (supplemental Fig. $5 a-d$, available at www.jneurosci.org as supplemental material), supporting the interpretation that increased MBH leucine and KIC availability decreased body weight by selectively reducing food intake.

Endogenous leucine metabolism in the MBH reduces food intake and body weight

The ability of MBH KIC to recapitulate the leucine-induced decrease in food intake suggests a role for endogenous leucine metabolism as a potent mechanism to account for leucine's anorexigenic effect. Indeed, leucine is solely ketogenic, and similarly to glucose and fatty acid, MBH leucine's effects on energy balance could be a consequence of its intracellular metabolism (He et al., 2006; Wolfgang and Lane, 2008). To test this suggestion, mice were implanted with an $\mathrm{MBH}$ osmotic minipump delivering $\mathrm{CIC}$, a specific repressor of branched-chain ketoacid dehydrogenase complex inhibitory kinase, resulting in a chronic activation of branched-chain amino acid irreversible decarboxylation (Harris et al., 1982). Chronic MBH CIC delivery induced a significant reduction in food intake during the $4 \mathrm{~d}$ following the minipump implantation (Fig. $2 a$ ) due to a decrease in daily meal number (Fig. $2 b$ ) compared with aCSF-injected controls, with no effect on meal size (Fig. $2 c$ ). Reduced food intake in mice receiving the CIC infusion was accompanied by a decreased rate of body weight gain (Fig. 2d). These data support the interpretation that $\mathrm{MBH}$ endogenous leucine metabolism contributes to leucine's anorexigenic effect, primarily by reducing meal frequency.

\section{MBH leucine activates MBH POMC neurons, and MBH} leucine's anorexigenic effect requires melanocortin signaling Because MBH KIC did not acutely affect eating, leucine metabolism within the $\mathrm{MBH}$ is not likely involved in the dramatic decrease in meal size measured as early as $20 \mathrm{~min}$ after MBH leucine administration. Therefore, we investigated alternative mechanisms to account for the acute effects of $\mathrm{MBH}$ leucine on meal size. Since central melanocortin signaling has been implicated in the control of meal size (Azzara et al., 2002), we evaluated the ability of leucine to activate anorexigenic POMC (proopiomelanocortin) neurons of the arcuate nucleus of the hypothalamus, using POMC-CRE Z/eGFP mice that express GFP specifically in POMC neurons. Incubation with leucine of POMC-CRE $\mathrm{Z}$ e/GFP mouse hypothalamic slices significantly increased the frequency of action potentials in arcuate hypothalamic POMC neurons (firing rate: control: $3.1 \pm 1.2 \mathrm{~Hz}$, range from 0 to $6.1 \mathrm{~Hz}$; leucine: $4.7 \pm 1.5 \mathrm{~Hz}$, range from 0.2 to $8.4 \mathrm{~Hz} ; n=5$ neurons; $p<0.05$ ) (Fig. 3a). Consistent with this result, $\mathrm{MBH}$ leucine injection induced c-Fos immunoreactivity in arcuate POMC 
neurons of POMC-CRE Z/eGFP mice (Fig. 3b,c). Interestingly, $\mathrm{MBH}$ leucine injection also induced c-Fos immunoreactivity in the PVN and the NTS (Fig. 3c), the former being involved in the integration of melanocortin signals arising from the MBH (Cowley et al., 2001; Blevins et al., 2004) while the latter integrates gutderived satiety signals with descending input from the forebrain to limit meal size (Moran et al., 2001; Berthoud et al., 2006). $\mathrm{MBH}$ leucine failed to induce c-Fos immunoreactivity in the $\mathrm{LH}, \mathrm{DMH}$, or the SON (Fig. 3c).

POMC neurons of the arcuate nucleus of the hypothalamus produce an endogenous agonist of melanocortin 3-4 receptors (MC3/4R), $\alpha$-melanocyte stimulating hormone ( $\alpha$-MSH) (Cone, 2005). Consequently, we assessed the effect of the melanocortin analog SHU9119, a MC3/4R antagonist, on $\mathrm{MBH}$ leucine-induced anorexia in mice. Coadministration of leucine with a subthreshold dose of SHU9119 (0.3 nmol, a dose that had no effect by itself on food intake and body weight) blocked $\mathrm{MBH}$ leucine-induced decreases in first meal size (Fig. $3 d$ ), food intake (Fig. 3e), and $24 \mathrm{~h}$ body weight change (Fig. $3 f$ ), indicating that MBH leucine's acute and longerterm effects on food intake and body weight require activation of MC3/4R. As MC3R have been primarily implicated in the negative feedback control of metabolism but not feeding (Chen et al., 2000), and MBH leucine's inhibitory effects on body weight gain were mediated solely by reductions in food intake and not energy expenditure, these findings support the interpretation that MC4R mediate MBH leucine's effects on food intake and body weight.

\section{MBH leucine activates PVN oxytocin anorexigenic neurons} PVN oxytocin neurons are activated by food consumption during a meal (Johnstone et al., 2006) and have been implicated in the melanocortinergic control of feeding by stimulating populations of neurons in the NTS that contribute to the control of meal size (Lokrantz et al., 1997) (Kublaoui et al., 2008) (Blevins et al., 2004). We next determined whether brainstem oxytocin signaling mediates the reduction in meal size produced by $\mathrm{MBH}$ leucine. Fourth ventricular administration of the oxytocin receptor antagonist OVT alone rapidly and dose-dependently increased food intake through a specific increase in meal size (supplemental Fig. 6, available at www.jneurosci.org as supplemental material), supporting for the first time a specific role for descending oxytocin tone in the control of meal size at the level of the caudal brainstem in mouse. Coadministration of $\mathrm{MBH}$ leucine and IVth intracerebroventricular OVT (30 min before leucine injections, where OVT had no effect by itself on feeding behavior) completely reversed the MBH leucine-induced decrease in food intake and meal size (Fig. 4). Together, these results demonstrate that $\mathrm{MBH}$ leucine sensing engages a forebrain-hindbrain circuit stemming from arcuate POMC neurons, involving activation of melanocortin signaling, PVN oxytocin neurons, and NTS neurons to reduce food intake by a specific reduction in meal size. b
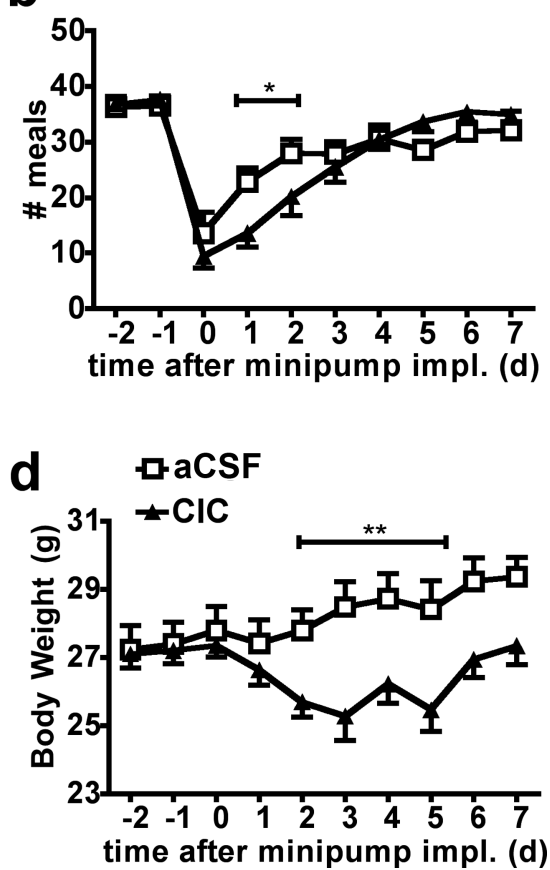

Figure 2. MBHCIC decreases food intake and body weight in mouse. $\boldsymbol{a}-\boldsymbol{d}$, Food intake $(\boldsymbol{a})$, meal number $(\boldsymbol{b})$, meal size $(\boldsymbol{c})$, and body weight $(\boldsymbol{d})$ in mouse infused for $8 \mathrm{~d}$ with aCSF $(n=8)$ or CIC $(n=10)$ in the MBH (injection design 2). Data are means \pm SEM. ${ }^{*} p<0.05 ;{ }^{* *} p<0.01$. impl., Implantation.

MBH leucine-induced activation of p70 S6 kinase 1 and Erk1/2 signaling pathways is required for leucine's anorexigenic effect

Finally, we investigated the intracellular signaling mechanisms activated by $\mathrm{MBH}$ leucine and required for its anorexigenic effect in mouse. p70 S6 kinase 1 (S6K) is a well described amino acid sensor (Kimball and Jefferson, 2006) and mediates the regulation of meal size in the MBH (Blouet et al., 2008). Consequently, we assessed the ability of MBH leucine to activate MBH S6K and its target ribosomal protein $\mathrm{S} 6$ ( $\mathrm{rS} 6$ ). We found a 2.3-fold increase in the expression of the activated forms of both S6K and rS6 in MBH extracts of leucine-injected mice compared with aCSF-injected controls $45 \mathrm{~min}$ after the injection (supplemental Fig. 7, available at www.jneurosci.org as supplemental material), positioning $\mathrm{MBH}$ leucine-induced activation of MBH S6K pathway as a good candidate mechanism to account for MBH leucine's acute effect on meal size.

Activation of the Erk1/2 signaling pathway occurs in PVN neurons and NTS neurons after activation of melanocortin signaling (Daniels et al., 2003; Sutton et al., 2004) and contributes to the regulation of meal size in NTS neurons (Sutton et al., 2005). In addition, refeeding rapidly activates Erk1/2 phosphorylation in PVN oxytocin neurons (supplemental Fig. 8, available at www. jneurosci.org as supplemental material). Consequently, we investigated the role of Erk1/2 signaling pathway in $\mathrm{MBH}$ leucine sensing. We found that $30 \mathrm{~min}$ after $\mathrm{MBH}$ leucine injection, the phosphorylation of Erk1/2 and its target the transcriptional factor CREB were increased in the $\mathrm{MBH}$, the PVN, and the DVC $($ Fig. $5 a-c)$. In the PVN, Erk1/2 phosphorylation was activated in oxytocin neurons following $\mathrm{MBH}$ leucine injection, as shown by oxytocin and phospho-Erk1/2 costaining in PVN slices of $\mathrm{MBH}$ leucine-injected mice (Fig. $5 d$ ). To further test the role of $\mathrm{MBH}$ Erk1/2 activation in MBH leucine's anorexigenic effect, we used U0126, a selective inhibitor of Erk1/2 upstream kinases MEK1 
a
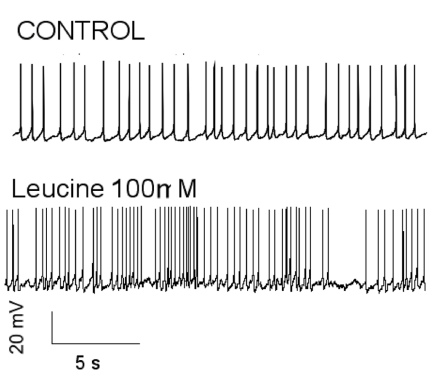

d

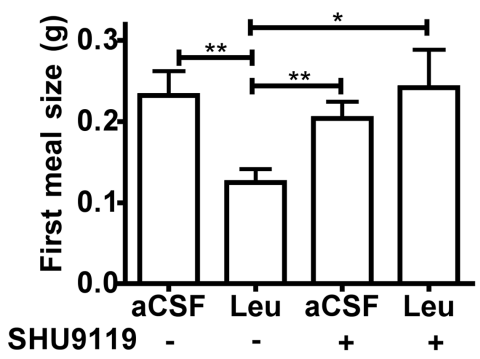

b

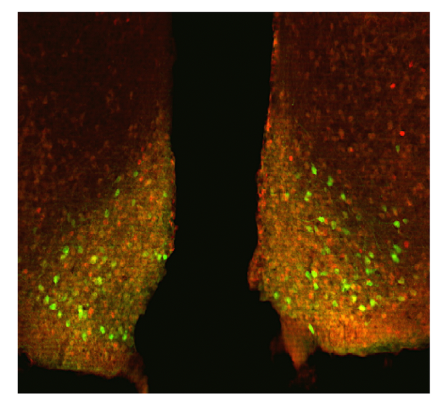

e

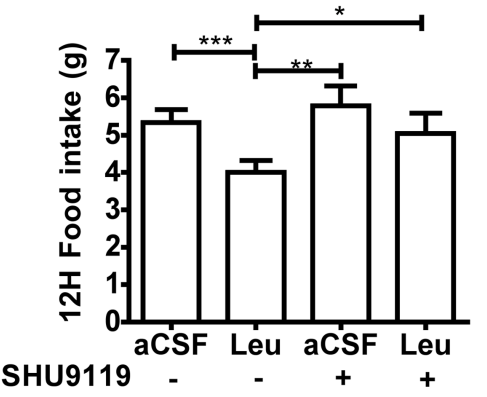

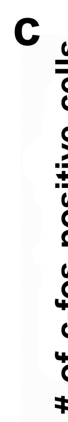

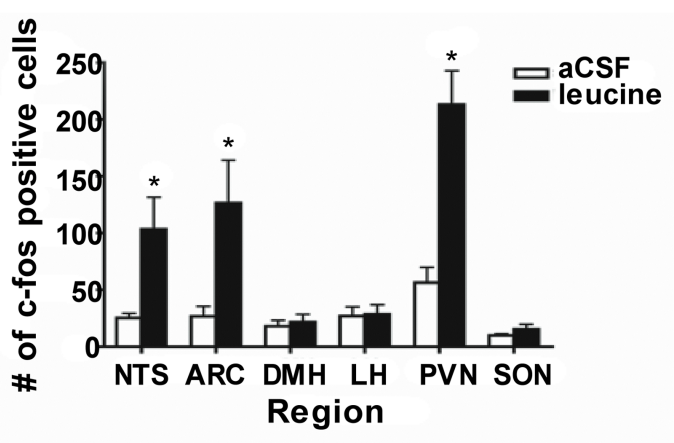

f

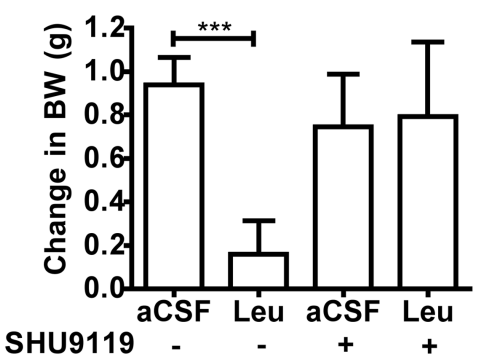

Figure 3. Leucine's anorexigenic effect requires direct activation of the melanocortin system. $\boldsymbol{a}$, Sample traces recorded before and after application of L-leucine from a POMC neuron in current-clamp configuration. $\boldsymbol{b}$, Immunofluorescence showing colocalization (yellow) of leucine-stimulated c-Fos-positive cells (Cy3, red) and arcuate POMC neurons of POMC-CRE Z/eGFP mice (green), 70 min after MBH leucine administration (injection design 1). $\boldsymbol{c}$, Quantification of c-Fos-positive cells in different nuclei 70 min after MBH aCSF or leucine injection (injection design 1). $\boldsymbol{d}-\boldsymbol{f}$, First meal size (d), $12 \mathrm{~h}$ food intake $(\boldsymbol{e})$, and $24 \mathrm{~h}$ change in body weight (BW) $(\boldsymbol{f})$ in mouse $(n=8-12)$ after MBH coadministration of SHU9119 or aCSF and leucine or aCSF (injection design 3$)$. Data are means \pm SEM. ${ }^{*} p<0.05 ;{ }^{* *} p<0.01 ;{ }^{* * *} p<0.001$.

a

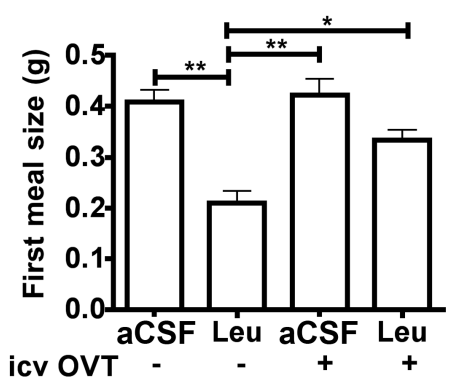

C

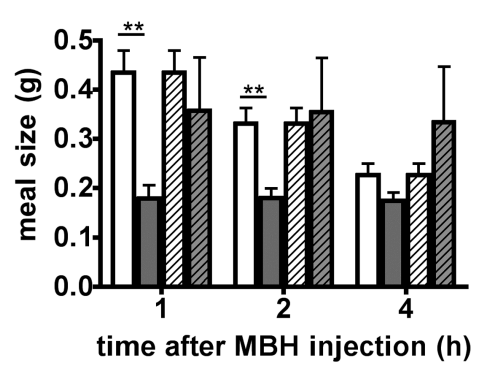

b

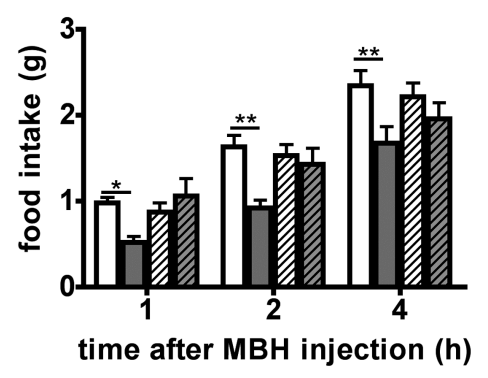

d

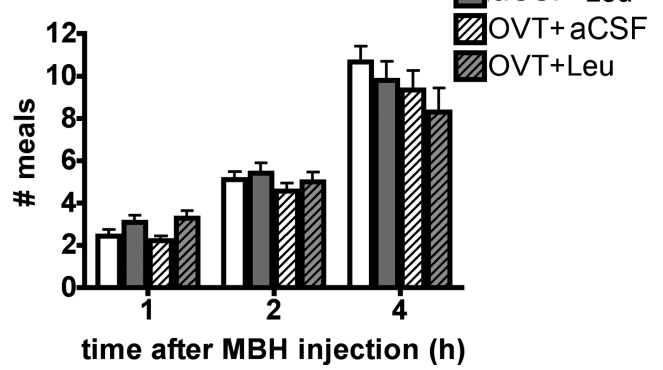

Figure 4. Oxytocin receptor antagonist blocks leucine anorexigenic effect. $\boldsymbol{a}-\boldsymbol{d}$, First meal size $(\boldsymbol{a})$, food intake (b), meal size $(\boldsymbol{c})$, and meal number $(\boldsymbol{d})$ in mouse $(n=9)$ after coadministration of IVth intracerebroventricular OVT or aCSF and MBH leucine or aCSF (injection design 5). Data are means \pm SEM. ${ }^{*} p<0.05 ;{ }^{* *} p<0.01$.

and MEK2. MBH administration of U0126 alone significantly increased food intake specifically by increasing meal size, increased body weight gain, and decreased MBH Erk1/2 Thr202/ Tyr204 phosphorylation (supplemental Fig. 9, available at www. jneurosci.org as supplemental material). Coadministration of
MBH leucine and MBH U0126 (25 ng, a dose that had no effect by itself on food intake and body weight) suppressed the leucine-induced decreases in first meal size (Fig. 6a), $24 \mathrm{~h}$ food intake (Fig. 6b), and 24 h body weight change (Fig. $6 c$ ). Western blot analysis of MBH extracts collected 45 min after the injections indicated that U0126 blocked leucine-induced activation of both Erk1/2 and S6K signaling pathways in the $\mathrm{MBH}$ (Fig. $6 d, e$ ). Together, these data indicate that local $\mathrm{MBH}$ administration of leucine induces the activation of $\mathrm{MBH}$ p70 S6 kinase 1, Erk1/2 signaling in $\mathrm{MBH}, \mathrm{PVN}$, and DVC neurons, and that $\mathrm{MBH}$ activation of these transducers is required for $\mathrm{MBH}$ leucine's anorexigenic effect.

\section{Discussion}

Despite the growing database supporting important roles for central nutrient sensing in the regulation of energy balance and the pathophysiology of obesity and metabolic diseases, the neurocircuit linking hypothalamic nutrient sensing to energy intake has not been identified. In this paper, we demonstrate for the first time that increased leucine availability specifically within the $\mathrm{MBH}$ engages a forebrain/hindbrain neurocircuitry that contributes to the negative feedback control of energy balance by reducing food intake. Our data provide evidence for a model of nutrient-activated hypothalamic neurocircuitry that 
a

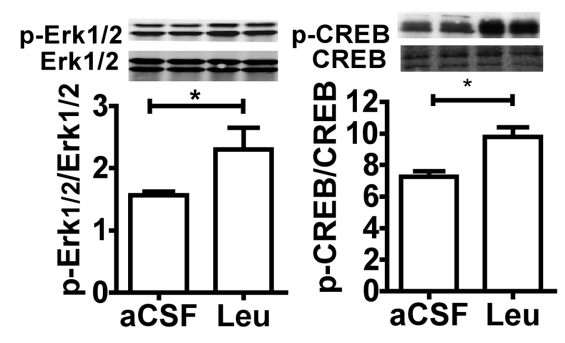

d

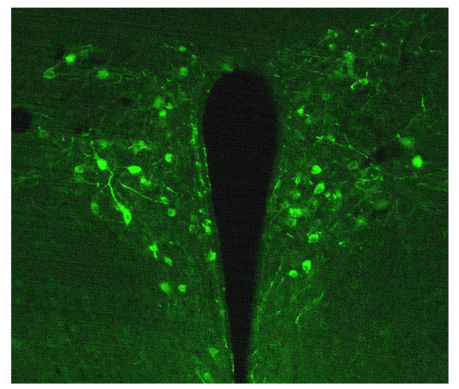

b

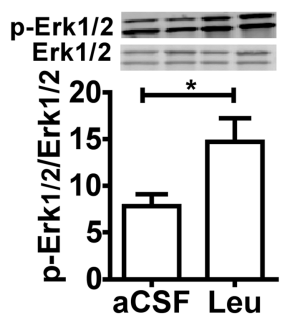

C

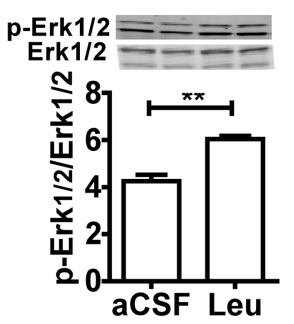

$\mathrm{p}-\mathrm{CREB}=2 \mathrm{z}=$

CREB

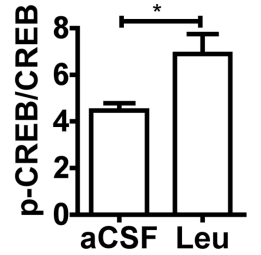

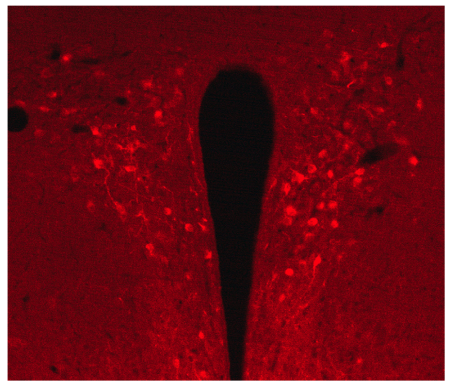

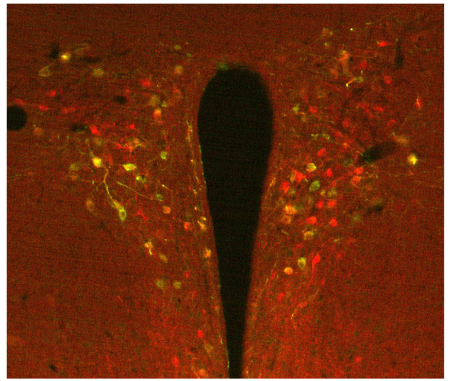

Figure 5. MBH leucine activates Erk1/2 signaling pathway in MBH, PVN oxytocin, and DVC neurons. $\boldsymbol{a}-\boldsymbol{c}$, MBH (a), PVN (b), and DVC (c) Erk1/2 Thr202/Tyr204 phosphorylation and CREB Ser133 phosphorylation in mouse $30 \mathrm{~min}$ after an MBH injection of aCSF $(n=5)$ or leucine $(n=5)$ (injection design 1).d, Immun ofluorescence showing colocalization (yellow, right) of oxytocin (Cy2, green, left) and MBH leucine-induced phospho-Thr202/Tyr204 Erk1/2 (Cy3, red, middle) in PVN slices of mice 30 min after MBH leucine administration (injection design 1).

transmits information from $\mathrm{MBH}$ nutrient sensors to brainstem neurons of the NTS implicated in the integrative control of ingestion.

The finding that dietary leucineinduced elevation in plasma leucine levels is associated with increased CSF leucine concentration supports the physiological relevance of this work. The $\mathrm{MBH}$ is located between the third ventricle and the median eminence, ideally situated to sense variations in blood and CSF circulating factors. The $25 \%$ postprandial increase in leucine CSF concentration observed following the ingestion of the HP meal is similar to that measured in PVN microdialysates (Choi et al., 2001). This work also reported a significant decrease in PVN microdialysate leucine concentration following the ingestion of a protein-free meal, indicating that the hypothalamus is exposed to bidirectional changes in leucine levels.

Our data support the interpretation that increased $\mathrm{MBH}$ leucine availability reduces body weight gain primarily by reducing ad libitum food intake, without affecting any contribution to energy expenditure. $\mathrm{MBH}$ KIC replicated $\mathrm{MBH}$ leucine effects, supporting both (1) the role of endogenous leucine in the control of food intake, since neuronal KIC is transaminated to leucine (Yudkoff et al., 2005), and (2) the role of endogenous leucine metabolism in leucine's anorexigenic effect, since KIC activates leucine decarboxylation (Hutson et al., 2005). This latter conclusion is confirmed by the decreased food intake and body weight gain we observed in mice receiving chronic $\mathrm{MBH}$ infusions of CIC, a selective activator of leucine irreversible decarboxylation. b
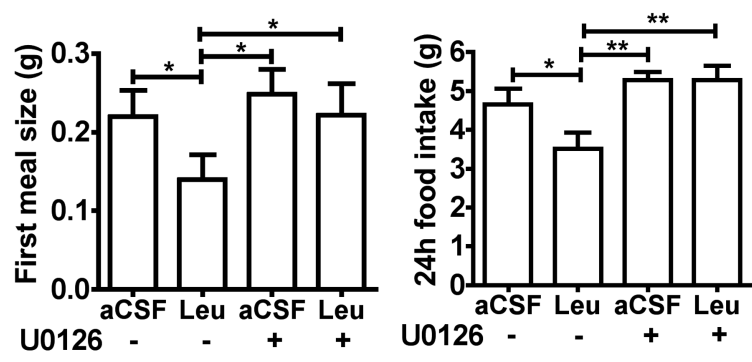

C

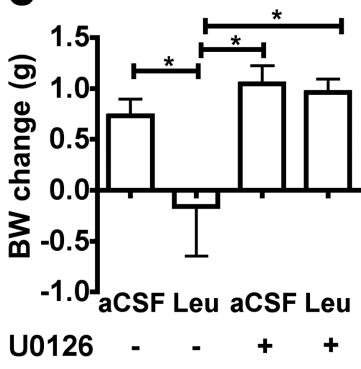

e

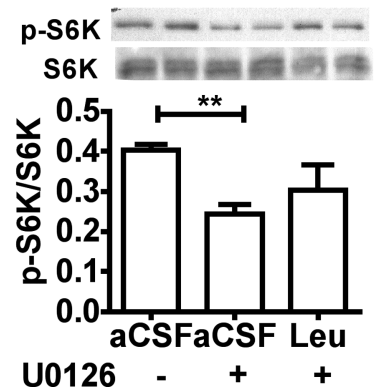

Figure 6. MBH leucine anorexigenic effect requires MBH Erk1/2 signaling. $\boldsymbol{a}-\boldsymbol{e}$, First meal size $(\boldsymbol{a}), 24 \mathrm{~h}$ food intake $(\boldsymbol{b}), 24 \mathrm{~h}$ change in body weight (BW) (c), MBH Erk1/2 Thr202/Tyr204 phosphorylation (d), and MBH p70 S6 kinase 1 Thr389 phosphorylation (e) in mouse $(n=6-12)$ after MBH coadministration of U0126 or its vehicle and leucine or aCSF (injection design 7$)$. All data are means \pm SEM. ${ }^{*} p<0.05 ;{ }^{* *} p<0.01$.

This represents the first demonstration that endogenous $\mathrm{MBH}$ leucine metabolism generates a signal that contributes to the regulation of energy balance. Interestingly, both $\mathrm{KIC}$ and $\mathrm{CIC} \mathrm{MBH}$ administrations decreased food intake selectively by reducing meal frequency, as has been reported after central inhibition of fatty-acid synthase with intracerebroventricular C75 (Aja et al., 2006). The inability of either valine or KIV to affect feeding suggests that the ketogenic fate of leucine is a requirement for its 


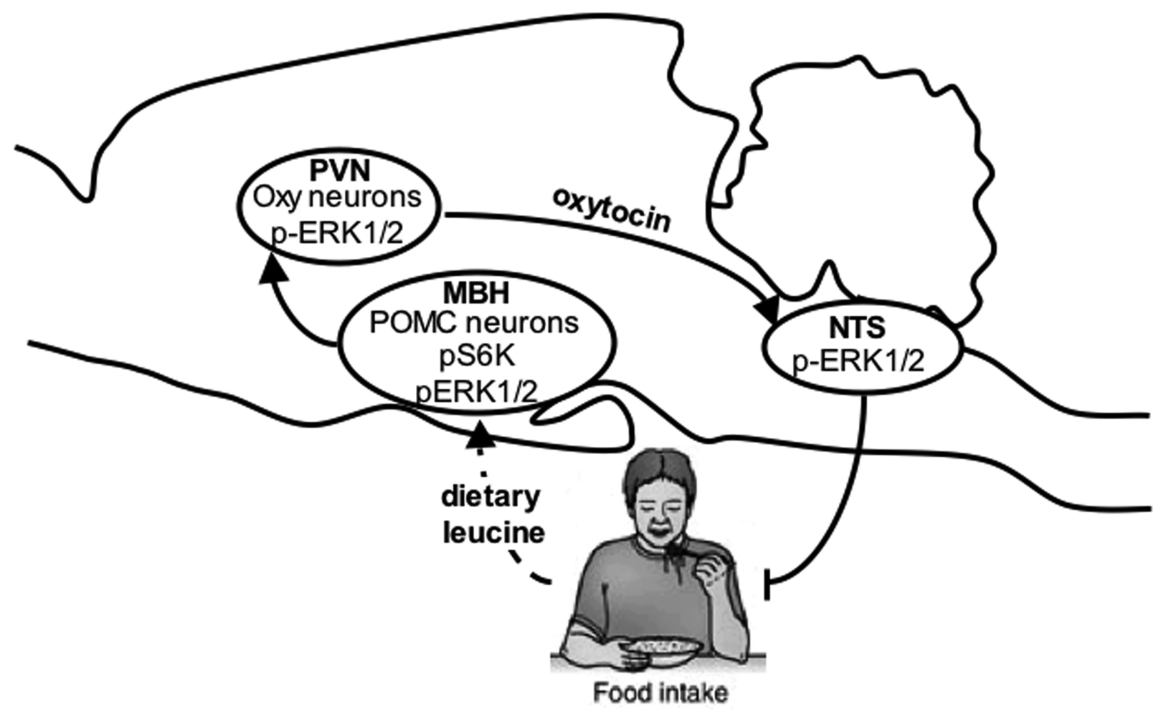

Figure 7. Model for MBH leucine's sensing regulation of feeding behavior. Acute increase in MBH leucine levels engages a forebrain/hindbrain neurocircuit to decrease meal size through the activation of MBH POMC neurons, PVN oxytocin neurons, and NTS neurons involved in the regulation of feeding.

ability to reduce food intake. Since hypothalamic glucose and fatty acid detection also involve their metabolism and the induced changes in the intracellular pool of malonyl-CoA/longchain fatty acyl-CoA (Lam et al., 2005), these data provide a framework for a synthetic understanding of MBH nutrient sensing mechanisms, where intracellular intermediates of macronutrients are used by nutrient sensing neurons to mediate the negative feedback control of energy balance.

A striking result of this study is the dramatic acute reduction in meal size observed shortly after $\mathrm{MBH}$ leucine administration. This effect is not replicated by $\mathrm{MBH}$ KIC, and likely involves alternative mechanisms than those described above. Our subsequent investigations gave us considerable insight into the neurobiological effectors of this rapid response.

The ability of SHU9119 to block both the acute and longerterm anorexia induced by $\mathrm{MBH}$ leucine demonstrates a critical role for hypothalamic melanocortin signaling in these feeding effects. Together with the ability of leucine to depolarize POMC neurons in vitro and acutely induce c-FOS gene expression in POMC neurons in vivo, these data support the interpretation that activation of POMC neurons and secretion of $\alpha-\mathrm{MSH}$ are involved in $\mathrm{MBH}$ leucine's acute reduction of meal size. In fact, both ARC neurons and their projection targets in the PVN express MC4 receptors (Bagnol et al., 1999; Kishi et al., 2003) and are activated shortly after $\mathrm{MBH}$ leucine administration, as evidenced by c-Fos expression and Erk1/2 phosphorylation.

Our work also demonstrates that (1) oxytocin exerts a tonic stimulatory effect on brainstem neurons that contribute to the control meal size, (2) rapid activation of Erk1/2 signaling in PVN oxytocin neurons accompanies refeeding, (3) MBH leucine activates PVN oxytocin neurons, and (4) the ability of $\mathrm{MBH}$ leucine to decrease meal size requires activation of oxytocin projections to DVC. As a population of PVN oxytocin neurons project directly to the NTS (Sawchenko and Swanson, 1982), these data support the interpretation that $\mathrm{MBH}$ leucine sensors activate the hypothalamic melanocortin system, which drives PVN oxytocin neurons projecting to the DVC, stimulating neurons of the nucleus of the solitary tract, implicated in the integrative regulation of meal size.
Together, these results represent the first comprehensive description of a functional neuroanatomical forebrainhindbrain circuit activated by $\mathrm{MBH}$ nutrient sensing to control food intake. Interestingly, leptin stimulates the same PVN/NTS circuit, and this activation contributes to leptin-induced reduction in meal size and increased NTS neuronal responses to visceral afferent satiety signals such as CCK (Emond et al., 2001; Blevins et al., 2004, 2009; Peters et al., 2008). Thus, the caudal brainstem integrates short-term nutrient availability signals from the forebrain, long-term adiposity signals, and short-term gut satiety signals, to determine the amount of food ingested during a meal.

Finally, we identified intracellular transducers of $\mathrm{MBH}$ leucine sensing, S6K and Erk1/2. MBH leucine rapidly induced $\mathrm{MBH}$ S6K phosphorylation, providing critical neuroanatomical specificity to a recent report that intracerebroventricular leucine activates the hypothalamic mTORC1 pathway (Cota et al., 2006). In light of results from recent studies demonstrating that overactivation of MBH S6K decreases food intake specifically by reducing meal size (Blouet et al., 2008), the present data support the interpretation that $\mathrm{MBH}$ leucine-induced activation of S6K mediates the acute decrease in meal size. In contrast to leucine, KIC is a poor activator of mTORC1 (Lynch et al., 2000), consistent with the present failure to observe any acute decrease in feeding following $\mathrm{MBH}$ KIC administration. Interestingly, $\mathrm{MBH}$ leucine administration was also associated with an activation of the Erk1/2 pathway in $\mathrm{MBH}, \mathrm{PVN}$, and DVC extracts. Furthermore, MBH Erk1/2 activation was required for leucine's effect on food intake and body weight, as shown by the ability of MBH U0126 to completely reverse MBH leucine's effects. The mechanism of leucine-induced activation of $\mathrm{MBH}$ Erk1/2 remains to be investigated, and could result from the molecular interaction between Erk1/2 and S6K signaling (Roux et al., 2007). The ability of U0126 to block leucine-induced activation of MBH S6K supports a direct interaction between leucine and the Erk1/2 pathway in $\mathrm{MBH}$ neurons. In contrast, activation of PVN Erk1/2 is likely secondary to $\mathrm{MBH}$ leucine-induced activation of melanocortin signaling, as indicated by our result that $\mathrm{MBH}$ leucine drives POMC neurons, and reports proposing that PVN Erk1/2 signaling is coupled to PVN MCR (Daniels et al., 2003). Coupling between MCR and Erk1/2 has also been shown in NTS neurons (Sutton et al., 2005), and we propose that DVC Erk1/2 activation results from PVN oxytocin neuron stimulation. In the NTS, Erk1/2 has been described as a molecular integrator of converging gut satiety signals and forebrain adiposity signals, required for both intraperitoneal CCK- and intracerebroventricular MTIIinduced anorexia (Sutton et al., 2004, 2005).

Our data (1) extend the integrative role of ERK1/2 in the control of food intake to include the feeding inhibitory consequences of $\mathrm{MBH}$ nutrient sensing and (2) identify activation of the Erk1/2 pathway as a common molecular effector of hypothalamic nutrient detection in $\mathrm{MBH}$ nutrient sensing neurons, $\mathrm{PVN}$ oxytocinergic relay neurons, and NTS neurons involved in the control of meal size. Interestingly, inhibition of Erk1/2 also completely reversed $\mathrm{MBH}$ leucine's longer-term effects on food in- 
take and $24 \mathrm{~h}$ body weight gain, most likely by activation of CREB, a direct regulator of gene expression. Together with our data showing (1) that Erk1/2 inhibition can overcome leucineinduced S6K activation and reduction in meal size and (2) that the $\mathrm{MBH}$ Erk1/2 pathway is also involved in natural satiation and satiety-as demonstrated by the ability of MBH U0126 to increase meal size, meal frequency, and body weight-our data strongly support the role of hypothalamic Erk1/2 as an important regulator and effector of feeding processes that has the potential to mediate acute and long-term changes in neuronal functioning.

Together, this work provides evidence for a model in which the $\mathrm{MBH}$ senses variations in leucine availability to regulate energy balance through multiple mechanisms (Fig. 7). Acute increases in $\mathrm{MBH}$ leucine availability engage a forebrain/hindbrain neurocircuit to decrease meal size through the activation of $\mathrm{MBH}$ POMC neurons, PVN oxytocin neurons, and NTS satiety effector neurons; within these three regions, this circuit involves Erk1/2 signaling, a molecular integrator of meal-size regulating signals. Over the longer term, we propose that increased $\mathrm{MBH}$ leucine levels decrease meal frequency by mechanisms involving leucine metabolism and activation of the transcription factor CREB. How this model can be expanded to include $\mathrm{MBH}$ sensing of other nutrients and the brainstem integration of multiple forebrain signals of nutrient abundance in the control of meal size remains to be determined.

\section{References}

Aja S, Bi S, Knipp SB, McFadden JM, Ronnett GV, Kuhajda FP, Moran TH (2006) Intracerebroventricular C75 decreases meal frequency and reduces AgRP gene expression in rats. Am J Physiol Regul Integr Comp Physiol 291:R148-R154.

Azzara AV, Sokolnicki JP, Schwartz GJ (2002) Central melanocortin receptor agonist reduces spontaneous and scheduled meal size but does not augment duodenal preload-induced feeding inhibition. Physiol Behav 77:411-416.

Bagnol D, Lu XY, Kaelin CB, Day HE, Ollmann M, Gantz I, Akil H, Barsh GS, Watson SJ (1999) Anatomy of an endogenous antagonist: relationship between Agouti-related protein and proopiomelanocortin in brain. J Neurosci 19:RC26.

Bensaïd A, Tomé D, L'Heureux-Bourdon D, Even P, Gietzen D, Morens C, Gaudichon C, Larue-Achagiotis C, Fromentin G (2003) A high-protein diet enhances satiety without conditioned taste aversion in the rat. Physiol Behav 78:311-320.

Berthoud HR, Sutton GM, Townsend RL, Patterson LM, Zheng H (2006) Brainstem mechanisms integrating gut-derived satiety signals and descending forebrain information in the control of meal size. Physiol Behav 89:517-524.

Blevins JE, Schwartz MW, Baskin DG (2004) Evidence that paraventricular nucleus oxytocin neurons link hypothalamic leptin action to caudal brain stem nuclei controlling meal size. Am J Physiol Regul Integr Comp Physiol 287:R87-R96.

Blevins JE, Morton GJ, Williams DL, Caldwell DW, Bastian LS, Wisse BE, Schwartz MW, Baskin DG (2009) Forebrain melanocortin signaling enhances the hindbrain satiety response to CCK-8. Am J Physiol Regul Integr Comp Physiol 296:R476-R484.

Blouet C, Ono H, Schwartz GJ (2008) Mediobasal hypothalamic p70 S6 kinase 1 modulates the control of energy homeostasis. Cell Metab 8:459-467.

Brosnan JT, Brosnan ME (2006) Branched-chain amino acids: enzyme and substrate regulation. J Nutr 136:207S-211S.

Chen AS, Marsh DJ, Trumbauer ME, Frazier EG, Guan XM, Yu H, Rosenblum CI, Vongs A, Feng Y, Cao L, Metzger JM, Strack AM, Camacho RE, Mellin TN, Nunes CN, Min W, Fisher J, Gopal-Truter S, MacIntyre DE, Chen HY, et al. (2000) Inactivation of the mouse melanocortin-3 receptor results in increased fat mass and reduced lean body mass. Nat Genet 26:97-102.

Choi YH, Fletcher PJ, Anderson GH (2001) Extracellular amino acid profiles in the paraventricular nucleus of the rat hypothalamus are influenced by diet composition. Brain Res 892:320-328.
Cone RD (2005) Anatomy and regulation of the central melanocortin system. Nat Neurosci 8:571-578.

Cota D, Proulx K, Smith KA, Kozma SC, Thomas G, Woods SC, Seeley RJ (2006) Hypothalamic mTOR signaling regulates food intake. Science 312:927-930.

Cowley MA, Smart JL, Rubinstein M, Cerdán MG, Diano S, Horvath TL, Cone RD, Low MJ (2001) Leptin activates anorexigenic POMC neurons through a neural network in the arcuate nucleus. Nature 411:480-484.

Daniels D, Patten CS, Roth JD, Yee DK, Fluharty SJ (2003) Melanocortin receptor signaling through mitogen-activated protein kinase in vitro and in rat hypothalamus. Brain Res 986:1-11.

Emond M, Schwartz GJ, Moran TH (2001) Meal-related stimuli differentially induce c-Fos activation in the nucleus of the solitary tract. Am J Physiol Regul Integr Comp Physiol 280:R1315-R1321.

Harris RA, Paxton R, DePaoli-Roach AA (1982) Inhibition of branched chain alpha-ketoacid dehydrogenase kinase activity by alphachloroisocaproate. J Biol Chem 257:13915-13918.

He W, Lam TK, Obici S, Rossetti L (2006) Molecular disruption of hypothalamic nutrient sensing induces obesity. Nat Neurosci 9:227-233.

Henquin JC, Dufrane D, Nenquin M (2006) Nutrient control of insulin secretion in isolated normal human islets. Diabetes 55:3470-3477.

Hutson SM, Sweatt AJ, Lanoue KF (2005) Branched-chain [corrected] amino acid metabolism: implications for establishing safe intakes. J Nutr 135:1557S-1564S.

Ibrahim N, Bosch MA, Smart JL, Qiu J, Rubinstein M, Rønnekleiv OK, Low MJ, Kelly MJ (2003) Hypothalamic proopiomelanocortin neurons are glucose responsive and express K(ATP) channels. Endocrinology 144:1331-1340.

Jo YH, Su Y, Gutierrez-Juarez R, Chua S Jr (2009) Oleic acid directly regulates POMC neuron excitability in the hypothalamus. J Neurophysiol 101:2305-2316.

Johnstone LE, Fong TM, Leng G (2006) Neuronal activation in the hypothalamus and brainstem during feeding in rats. Cell Metab 4:313-321.

Kanamori K, Ross BD, Kondrat RW (1998) Rate of glutamate synthesis from leucine in rat brain measured in vivo by $15 \mathrm{~N}$ NMR. J Neurochem 70:1304-1315.

Kimball SR, Jefferson LS (2006) New functions for amino acids: effects on gene transcription and translation. Am J Clin Nutr 83:500S-507S.

Kishi T, Aschkenasi CJ, Lee CE, Mountjoy KG, Saper CB, Elmquist JK (2003) Expression of melanocortin 4 receptor mRNA in the central nervous system of the rat. J Comp Neurol 457:213-235.

Kublaoui BM, Gemelli T, Tolson KP, Wang Y, Zinn AR (2008) Oxytocin deficiency mediates hyperphagic obesity of Sim1 haploinsufficient mice. Mol Endocrinol 22:1723-1734.

Lam TK, Schwartz GJ, Rossetti L (2005) Hypothalamic sensing of fatty acids. Nat Neurosci 8:579-584.

Lokrantz CM, Uvnäs-Moberg K, Kaplan JM (1997) Effects of central oxytocin administration on intraoral intake of glucose in deprived and nondeprived rats. Physiol Behav 62:347-352.

Lugarini F, Hrupka BJ, Schwartz GJ, Plata-Salaman CR, Langhans W (2002) A role for cyclooxygenase-2 in lipopolysaccharide-induced anorexia in rats. Am J Physiol Regul Integr Comp Physiol 283:R862-R868.

Lynch CJ, Fox HL, Vary TC, Jefferson LS, Kimball SR (2000) Regulation of amino acid-sensitive TOR signaling by leucine analogues in adipocytes. J Cell Biochem 77:234-251.

Moran TH, Ladenheim EE, Schwartz GJ (2001) Within-meal gut feedback signaling. Int J Obes Relat Metab Disord 25 [Suppl 5]:S39-S41.

Morton GJ, Cummings DE, Baskin DG, Barsh GS, Schwartz MW (2006) Central nervous system control of food intake and body weight. Nature 443:289-295.

Nair KS, Schwartz RG, Welle S (1992) Leucine as a regulator of whole body and skeletal muscle protein metabolism in humans. Am J Physiol 263:E928-E934.

Obici S, Feng Z, Morgan K, Stein D, Karkanias G, Rossetti L (2002) Central administration of oleic acid inhibits glucose production and food intake. Diabetes 51:271-275.

Parton LE, Ye CP, Coppari R, Enriori PJ, Choi B, Zhang CY, Xu C, Vianna CR, Balthasar N, Lee CE, Elmquist JK, Cowley MA, Lowell BB (2007) Glucose sensing by POMC neurons regulates glucose homeostasis and is impaired in obesity. Nature 449:228-232.

Paxinos G, Franklin KBJ (2001) The mouse brain in stereotaxic coordinates, Ed 2. New York: Academic. 
Peters JH, McDougall SJ, Kellett DO, Jordan D, Llewellyn-Smith IJ, Andresen MC (2008) Oxytocin enhances cranial visceral afferent synaptic transmission to the solitary tract nucleus. J Neurosci 28:11731-11740.

Pocai A, Lam TK, Obici S, Gutierrez-Juarez R, Muse ED, Arduini A, Rossetti L (2006) Restoration of hypothalamic lipid sensing normalizes energy and glucose homeostasis in overfed rats. J Clin Invest 116:1081-1091.

Proud CG (2004) mTOR-mediated regulation of translation factors by amino acids. Biochem Biophys Res Commun 313:429-436.

Roux PP, Shahbazian D, Vu H, Holz MK, Cohen MS, Taunton J, Sonenberg N, Blenis J (2007) RAS/ERK signaling promotes site-specific ribosomal protein S6 phosphorylation via RSK and stimulates cap-dependent translation. J Biol Chem 282:14056-14064.

Sawchenko PE, Swanson LW (1982) Immunohistochemical identification of neurons in the paraventricular nucleus of the hypothalamus that project to the medulla or to the spinal cord in the rat. J Comp Neurol 205:260-272.

Sutton GM, Patterson LM, Berthoud HR (2004) Extracellular signal- regulated kinase $1 / 2$ signaling pathway in solitary nucleus mediates cholecystokinin-induced suppression of food intake in rats. J Neurosci 24:10240-10247.

Sutton GM, Duos B, Patterson LM, Berthoud HR (2005) Melanocortinergic modulation of cholecystokinin-induced suppression of feeding through extracellular signal-regulated kinase signaling in rat solitary nucleus. Endocrinology 146:3739-3747.

Wang R, Liu X, Hentges ST, Dunn-Meynell AA, Levin BE, Wang W, Routh VH (2004) The regulation of glucose-excited neurons in the hypothalamic arcuate nucleus by glucose and feeding-relevant peptides. Diabetes 53:1959-1965.

Wolfgang MJ, Lane MD (2008) Hypothalamic malonyl-coenzyme A and the control of energy balance. Mol Endocrinol 22:2012-2020.

Yudkoff M, Daikhin Y, Nissim I, Horyn O, Luhovyy B, Lazarow A, Nissim I (2005) Brain amino acid requirements and toxicity: the example of leucine. J Nutr 135:1531S-1538S. 